\title{
Vasopressors and Inotropes in the Treatment of Human Septic Shock: Effect on Innate Immunity?
}

\author{
Koen J. Hartemink, ${ }^{1,2,3}$ and A. B. Johan Groeneveld ${ }^{1}$
}

\begin{abstract}
Catecholamines have been suggested to modulate innate immune responses in experimental settings. The significance hereof in the treatment of human septic shock is unknown. We therefore sought if and how vasopressor/inotropic doses relate to pro-inflammatory mediators during treatment of septic shock. We prospectively studied 20 consecutive septic shock patients. For 3 days after admission, hemodynamic variables, lactate and plasma levels of interleukins (IL)-6 and 8, tumor necrosis factor (TNF)- $\alpha$, and elastase- $\alpha_{1}$-antitrypsin were measured six hourly. Doses of vasoactive drugs were recorded. Of the 20 patients, nine died in the intensive care unit. Dobutamine doses were positively associated and related to TNF- $\alpha$ plasma levels, independently of disease severity, hemodynamics, and outcome, in multivariable models. Dopamine doses were positively associated with IL-6, and norepinephrine was inversely associated with IL-8 and TNF- $\alpha$ levels. Our observations suggest that catecholamines used in the treatment of human septic shock differ in their potential modulation of the innate immune response to sepsis in vivo. Dobutamine treatment may contribute to circulating TNF- $\alpha$ and dopamine to IL-6, independently of activated neutrophils. Conversely, norepinephrine may lack pro-inflammatory actions.
\end{abstract}

KEY WORDS: catecholamines; innate immunity; septic shock; immunomodulation; adrenergic receptors.

\section{INTRODUCTION}

Human septic shock is characterized by release of pro-inflammatory mediators in the host defense against invading microorganisms, which overwhelms antiinflammatory mediators, following activation of the complement system and neutrophils and production of cytokines such as tumor necrosis factor-alpha (TNF- $\alpha$ ) and interleukins [1-5]. Vasopressor and inotropic drugs commonly used in the treatment of the syndrome to augment arterial blood pressure and cardiac function have been suggested to down- or upregulate innate immunity in experimental settings with contradicting results, depending on models, species, challenges, drugs, and adrenergic receptors [6-22]. It has been suggested

\footnotetext{
${ }^{1}$ Department of Intensive Care and the Institute for Cardiovascular Research, VU University Medical Center, Amsterdam, The Netherlands

${ }^{2}$ Department of Surgery, VU University Medical Center, De Boelelaan 1117, 1081, HV Amsterdam, The Netherlands

${ }^{3}$ To whom correspondence should be addressed at Department of Surgery, VU University Medical Center, De Boelelaan 1117, 1081, HV Amsterdam, The Netherlands. E-mail: kjhartemink@hetnet.nl; E-mail: k.hartemink@vumc.nl
}

that the use of drugs in the hemodynamic management of human septic shock may modulate immune responses in vivo and thereby contribute to their effects on outcome, even independently of hemodynamics $[8,20$, $23,24]$. In experimental human endotoxemia, for instance, low doses of $\beta$-adrenergic dobutamine did not inhibit circulating innate immune responses, while epinephrine did [25]. In contrast, in a single randomized clinical trial, dobutamine was suggested to increase hepatosplanchnic release of TNF- $\alpha$ in septic shock, as compared to treatment by enoximone [26]. The interest for catecholamine-induced modulation of immune responses has recently been revived by the observation that endogenous, neutrophil-derived catecholamines play an important (autocrine) role in the host defense during experimental sepsis [10,27]. There are no in vivo data to support any action of catecholamine drugs on inflammatory responses.

To further elucidate a potential role in vivo of drug treatment of human septic shock in modulating innate immunity, we measured, at six-hourly intervals, proinflammatory mediators and recorded vasopressor/inotropic drug doses in 20 consecutive septic shock patients 
until $72 \mathrm{~h}$ after admission in the intensive care unit (ICU) and studied longitudinal associations and relations between variables in the course of disease.

\section{MATERIALS AND METHODS}

\section{Patients}

We prospectively studied 20 consecutive patients admitted into the ICU because of septic shock, not receiving corticosteroid treatment. After obtaining informed consent in each eligible patient or closest relative, patients were enrolled within $12 \mathrm{~h}$ after admission. The study had been approved by the Institutional Review Board and the Hospital Committee on Ethics. Criteria for septic shock were clinical evidence of infection, temperature above $38.5^{\circ} \mathrm{C}$ or below $36.0^{\circ} \mathrm{C}$, tachycardia ( $>90$ beats $/ \mathrm{min}$ ), and tachypnea $(>20 / \mathrm{min})$ or necessity for mechanical ventilation. Shock was defined as a fall in systolic arterial blood pressure below $90 \mathrm{mmHg}$ or by more than $30 \mathrm{mmHg}$ in prior hypertensive patients (in the absence of other causes of hypotension and despite adequate fluid administration), or need for administration of vasoactive therapy, together with at least one sign of inadequate tissue perfusion (oliguria, mental alterations, hyperlactatemia).

\section{Therapeutic Protocol}

Patients were monitored with help of an arterial catheter for measurement of mean arterial pressure (MAP; millimeters of mercury) and by a pulmonary artery catheter $(n=14)$ for measurement of cardiac output (CO; liters per minute), central venous pressure (CVP; millimeters of mercury), mean pulmonary artery pressure (millimeters of mercury), and pulmonary artery occlusion pressure (millimeters of mercury). In the absence of a pulmonary artery catheter, CVP monitoring was done with help of a central venous catheter. The heart rate (beats per minute) was recorded continuously. Patients were treated by attending physicians not involved in the study, with help of antibiotics (after taking appropriate samples for culture), fluids, and vasoactive drugs through continuous infusions, as guided by the clinical and hemodynamic response. Dopamine, dobutamine, and/or norepinephrine were infused if an increase in forward blood flow or pressure, respectively, was considered necessary, on clinical ground. Blood cultures were taken when clinically indicated. Local specimens for culture were collected depending on a suspected focus of infection. Blood cultures were processed using delayed vial entry bottles for aerobic and anaerobic cultures and Bactec 94/9240 automatic analyzers (Becton-Dickinson, Erembodegem, Belgium). Bottles were incubated for a maximum of 7 days. If the analyzers showed growth, Gram stains were prepared and the sensitivity of the organisms for antibiotics was assessed. Local cultures were processed according to standardized procedures. Mechanical ventilation was instituted in all but one patient.

\section{Study Protocol}

Patient variables, such as age, gender, underlying disease, source of sepsis, blood, and local culture results, were recorded. Variables necessary to compute the Acute Physiology and Chronic Health Evaluation (APACHE)II score were recorded and used to estimate severity of disease in critically ill patients. For 3 days (days 0,1 , and 2) after admission, patients entered a six-hourly hemodynamic measurement and blood sampling schedule, at $3.00,9.00,15.00$, and $21.00 \mathrm{~h}$, as soon as possible after enrollment (beginning at day 0 ). In our unit, pulmonary artery catheters are removed $72 \mathrm{~h}$ after insertion to prevent catheter-related infection. Hemodynamic variables were measured with patients in the supine position, after calibration and zeroing to atmospheric pressure at the midchest level (Viggo-Spectramed, Spectramed, Bilthoven, The Netherlands; monitor Tramscope ${ }^{\mathrm{R}}$, Marquette Electronics, Milwaukee, WI, USA), at end-expiration. For CO measurements, the average of triplicate injections of $10 \mathrm{~mL}$ of $\mathrm{D} 5 \mathrm{~W}$ at room temperature, at random in the respiratory cycle, was used. The doses of concomitantly infused vasoactive drugs were recorded. Hemodynamic measurements were performed until the pulmonary artery catheter was taken out by the attending physicians or until death. Heparin-anticoagulated blood was taken six hourly from the arterial catheter to determine plasma lactate levels and daily to determine creatinine plasma levels. Blood samples for the determination of plasma levels of proinflammatory mediators that are commonly implicated in the pathogenesis of severe sepsis and shock were obtained at inclusion and every $6 \mathrm{~h}$. The samples were collected in tubes containing soybean trypsin inhibitor $(100 \mu \mathrm{g} / \mathrm{mL}$, final concentration), ethylenediaminetetraacetate $(10 \mathrm{mmol} / \mathrm{L})$, and benzamidine $(10 \mathrm{mmol} / \mathrm{L})$ to prevent in vitro activation. All tubes were centrifuged for $10 \mathrm{~min}$ at $1,300 \times \mathrm{g}$, and aliquots of the plasma were stored immediately at $-70^{\circ} \mathrm{C}$ until assayed. The length of stay until discharge from, or death in the ICU, was recorded. 
Patients were considered to have survived septic shock if alive until discharge from the ICU.

\section{Assays}

Lactate concentrations (normal value $<1.8 \mathrm{mmol} / \mathrm{L}$ ) and creatinine (normal value $<130 \mu \mathrm{mol} / \mathrm{L}$ ) concentrations in plasma were determined with help of an analyzer (Boehringer-Mannheim Hitachi analyzers 911 and 747, Almere, The Netherlands). Plasma interleukin (IL)-6 levels were measured by an enzyme-linked immunosorbent assay using the monoclonal antibody CLB.IL-6 [3]. Results were related to dose-response curves obtained with recombinant IL-6 and expressed as picograms per milliliter. The upper limit of normal is $10 \mathrm{pg} / \mathrm{mL}$. IL-8 was measured by an ELISA in which antibodies to human recombinant IL-8 (rIL-8; British Biotechnology Ltd, Oxford, UK) were used. Plates were coated with a monoclonal antibody against rIL-8 (CLB3.IL-8), and bound IL-8 was detected by a biotinylated monoclonal antibody. The lower detection limit is $<5 \mathrm{pg} / \mathrm{mL}$ with normal values below $20 \mathrm{pg} / \mathrm{mL}$. The TNF- $\alpha$ plasma concentration was measured by enzyme immunoassay (Innogenetics, Zwijnaarde, Belgium), with an interassay variation of $9 \%$ and an intra-assay variation ranging from $0.8 \%$ to $8 \%$; the lower limit of detection is $4 \mathrm{pg} / \mathrm{mL}$ and normal values are less than $20 \mathrm{pg} / \mathrm{mL}$. Elastase- $\alpha_{1}$-antitrypsin was measured with help of a radioimmunoassay. Normal values for elastase- $\alpha_{1}$-antitrypsin are $<100 \mathrm{ng} / \mathrm{mL}$. The intra- and interassay variation coefficients for the assays described were $<15$ and $<20 \%$, respectively.

\section{Calculations and Statistical Analysis}

Cardiac index (CI) was calculated as CO/body surface area (liters per minute per square meter). If necessary, values were logarithmically transformed to obtain normal distributions (Kolmogorov-Smirnov test $P>0.05$ ). To study doses of vasopressor/inotropic drugs in relation to pro-inflammatory mediators, generalized estimating equations (GEE) were done, to take repeated measurements in the same patients into account; we entered APACHE-II, MAP, CI, and survival as covariates to adjust for disease severity, hemodynamics, and outcome. The standardized regression coefficient was calculated from the regression coefficient multiplied by the ratio of standard deviations. Differences between groups in initial, highest, and final values for hemodynamic and pro-inflammatory mediators were evaluated using the non-parametric Mann-Whitney $U$ test. For dobutamine, the partial correlation coefficient $(r)$, with patient number and time as covariates, was used to evaluate relations for pooled data, taking repeated measurements in the same patients into account, as well as APACHE-II scores and MAP. Exact $P$ values are given if $>0.001$ and were considered statistically significant if $<0.05$. Values are median and range in text and tables and mean \pm standard error of the mean (SEM) in figures.

\section{RESULTS}

\section{Patient Characteristics}

Table 1 describes patient characteristics. Nine patients $(45 \%)$ died in the ICU, four of them within 3 days after admission. On day 1 , two patients died and one patient was discharged from the ICU. On day 2, one

Table 1. Patient Characteristics

\begin{tabular}{|c|c|}
\hline Age (years) & $65(21-83)$ \\
\hline Gender (male/female) & $12 / 8$ \\
\hline \multicolumn{2}{|l|}{ Underlying disease } \\
\hline COPD & 3 \\
\hline Diabetes mellitus & 1 \\
\hline Ischemic heart disease & 3 \\
\hline Liver cirrhosis & 6 \\
\hline Malignancy & 7 \\
\hline Renal insufficiency & 1 \\
\hline Vascular disease & 1 \\
\hline Other & 4 \\
\hline \multicolumn{2}{|l|}{ Source of sepsis } \\
\hline Cholecystitis/cholangitis & 2 \\
\hline Diverticulitis & 1 \\
\hline Ischemic colitis & 1 \\
\hline Mediastinitis & 1 \\
\hline Respiratory tract infection & 7 \\
\hline Urinary tract infection & 4 \\
\hline Genital tract infection & 1 \\
\hline Endocarditis & 1 \\
\hline Skin & 2 \\
\hline APACHE-II score & $31(15-41)$ \\
\hline Mechanical ventilation & 18 \\
\hline Vasopressor/inotropic treatment & 20 \\
\hline Serum creatinine $(\mu \mathrm{mol} / \mathrm{L})$ & $177(49-675)$ \\
\hline Renal replacement therapy & 6 \\
\hline Duration of observation (h) & $72(6-72)$ \\
\hline Length of stay in the ICU (days) & $5(1-29)$ \\
\hline Mortality in the ICU & 9 \\
\hline
\end{tabular}


patient died and one patient was discharged from the ICU. On day 3, one patient died and one patient was discharged from the ICU, leaving 13 patients in the study at $72 \mathrm{~h}$ after inclusion.

\section{Hemodynamics}

As seen in Table 2, patients had a hyperdynamic circulation with tachycardia, mild hypotension, and increased CI. Mean arterial pressure was lower and CVP, and lactate plasma levels were higher in nonsurvivors compared to survivors. Non-survivors had more vasopressor drugs administered compared to survivors (Table 3 ). Seven patients had received dobutamine at any point of the disease course. Non-survivors had persistent lactic acidosis.

\section{Pro-inflammatory Mediators}

IL-6 and IL-8 plasma levels were elevated above normal in 189 of 195 (97\%) and 190 of 195 (97\%) measurements, respectively. TNF- $\alpha$ plasma levels were elevated above normal in 125 of $160(78 \%)$ and elastase$\alpha_{1}$-antitrypsin in 126 of 195 (65\%) measurements. Inflammatory mediators did not differ between survivors and non-survivors, besides final IL- 8 levels which were higher in non-survivors (Table 3). The seven patients receiving dobutamine in the disease course had higher TNF- $\alpha$ levels $(47[6-130] \mathrm{pg} / \mathrm{mL})$ than those not receiving dobutamine (30 [5-301] pg/mL), independently of APACHE-II scores, MAP, CI, use of other drugs, and outcome (GEE, $P<0.001$ ).

\section{Associations and Relations Between Vasopressor Doses and Innate Immunity}

Figure 1 shows that TNF- $\alpha$ plasma levels fell less in the seven septic shock patients with dobutamine compared to the 13 patients without dobutamine. Table 4 shows that plasma levels of TNF- $\alpha$ were higher in those patients receiving dobutamine than in those not receiving the drug, independent of APACHE-II, MAP, CI, and use of other drugs. In a multivariable analysis including outcome, dobutamine doses were positively associated with TNF- $\alpha$ levels (standardized regression coefficient $0.57, P<0.001$ ), independently of APACHE-II, hypotension $(P=0.031), \mathrm{CI}$, and non-survival $(P=0.007)$. The partial correlation coefficient for the relation between TNF- $\alpha$ and dobutamine, adjusted for repeated measurements and APACHE II score, was $0.38(P<0.001)$. Figure 2 shows the relation between

Table 2. Hemodynamic Variables and Vasopressors/Inotropics in the Course of Disease in Outcome Groups

\begin{tabular}{|c|c|c|c|c|}
\hline & & $\begin{array}{l}\text { Survivors } \\
n=11\end{array}$ & $\begin{array}{l}\text { Non-survivors } \\
n=9\end{array}$ & $P$ \\
\hline \multirow[t]{4}{*}{$\mathrm{HR}$, beats/min } & I & $118(105-150)$ & $126(97-143)$ & 0.73 \\
\hline & $\mathrm{H}$ & $120(105-176)$ & $130(100-159)$ & 0.91 \\
\hline & $\mathrm{L}$ & $100(68-133)$ & $116(90-130)$ & 0.23 \\
\hline & $\mathrm{F}$ & $107(61-133)$ & $130(90-146)$ & 0.22 \\
\hline \multirow[t]{4}{*}{ MAP, $\mathrm{mmHg}$} & I & $70(53-100)$ & $63(49-82)$ & 0.27 \\
\hline & $\mathrm{H}$ & $90(76-100)$ & $80(49-96)$ & 0.14 \\
\hline & $\mathrm{L}$ & $58(46-80)$ & $56(42-72)$ & 0.34 \\
\hline & $\mathrm{F}$ & $76(70-91)$ & $56(42-91)$ & 0.03 \\
\hline \multirow[t]{4}{*}{$\mathrm{CVP}, \mathrm{mmHg}$} & I & $8(4-13)$ & $9(4-18)$ & 0.30 \\
\hline & $\mathrm{H}$ & $11(6-15)$ & $17(11-21)$ & 0.003 \\
\hline & $\mathrm{L}$ & $5(4-8)$ & $7(2-18)$ & 0.76 \\
\hline & $\mathrm{F}$ & $7(5-15)$ & $12(5-22)$ & 0.03 \\
\hline \multirow[t]{3}{*}{$\mathrm{CI}, \mathrm{L} / \mathrm{min} / \mathrm{m}^{2}$} & $\mathrm{I}$ & $4.2(2.1-6.2)$ & $3.4(1.8-7.2)$ & 0.90 \\
\hline & $\mathrm{L}$ & $1.6(2.1-5.2)$ & $2.6(1.5-6.8)$ & 0.52 \\
\hline & $\mathrm{F}$ & $3.7(2-6)$ & $3.2(2.0-6.8)$ & 0.52 \\
\hline \multirow[t]{4}{*}{ Lactate, $\mathrm{mmol} / \mathrm{L}$} & I & $1.7(1.0-5.1)$ & $2.6(0.9-10.0)$ & $<0.001$ \\
\hline & $\mathrm{H}$ & $2.0(1.3-5.1)$ & $3.5(1.1-11.6)$ & 0.14 \\
\hline & $\mathrm{L}$ & $1.0(0.7-2.0)$ & $1.9(0.7-10.0)$ & 0.05 \\
\hline & $\mathrm{F}$ & $1.1(0.9-2.0)$ & $2.4(1.0-11.6)$ & 0.01 \\
\hline
\end{tabular}

Median (range) and Mann-Whitney $U$ test

$H R$ heart rate (beats per minute), $M A P$ mean arterial pressure, $C V P$ central venous pressure, $C I$ cardiac index. $I$ initial, $H$ highest, $L$ lowest, $F$ final values in the course of time 
Table 3. Course of pro-inflammatory mediators and drug doses in outcome groups

\begin{tabular}{|c|c|c|c|}
\hline & $\begin{array}{l}\text { Survivors } \\
n=11\end{array}$ & $\begin{array}{l}\text { Non-survivors } \\
n=9\end{array}$ & $P$ \\
\hline \multicolumn{4}{|c|}{ Inflammatory mediators } \\
\hline \multicolumn{4}{|c|}{ IL-6, pg/mL } \\
\hline I & $293(17-60,152)$ & $475(74-161,787)$ & 0.77 \\
\hline $\mathrm{H}$ & $320(31-60,152)$ & $761(197-161,787)$ & 0.55 \\
\hline $\mathrm{F}$ & $48(4-426)$ & $133(9-161,787)$ & 0.11 \\
\hline \multicolumn{4}{|c|}{$\mathrm{IL}-8, \mathrm{pg} / \mathrm{mL}$} \\
\hline $\mathrm{I}$ & $573(29-10,429)$ & $1,357(98-12,741)$ & 0.26 \\
\hline $\mathrm{H}$ & $843(47-10,458)$ & $1,648(225-12,741)$ & 0.41 \\
\hline $\mathrm{F}$ & $85(7-1,085)$ & $345(52-12,741)$ & 0.04 \\
\hline \multicolumn{4}{|c|}{$\mathrm{TNF}-\alpha, p g / \mathrm{mL}$} \\
\hline I & $49(17-301)$ & $56(9-79)$ & 0.46 \\
\hline $\mathrm{H}$ & $66(39-301)$ & $56(19-90)$ & 0.30 \\
\hline $\mathrm{F}$ & $30(5-82)$ & $26(5-90)$ & 0.94 \\
\hline \multicolumn{4}{|c|}{ Elastase- $\alpha_{1}$-antitrypsin, $\mathrm{ng} / \mathrm{mL}$} \\
\hline I & $145(10-716)$ & $131(12-707)$ & 0.82 \\
\hline $\mathrm{H}$ & $200(18-721)$ & $168(12-905)$ & 0.77 \\
\hline $\mathrm{F}$ & $98(18-570)$ & $160(9-405)$ & 0.60 \\
\hline \multicolumn{4}{|c|}{ Drug doses } \\
\hline \multicolumn{4}{|c|}{ Dopamine, $\mu \mathrm{g} / \mathrm{kg} / \mathrm{min}$} \\
\hline I & $8(0-19)$ & $17(8-22)$ & 0.007 \\
\hline $\mathrm{H}$ & $12(0-19)$ & $19(8-27)$ & 0.012 \\
\hline $\mathrm{F}$ & $2(0-16)$ & $19(5-27)$ & $<0.001$ \\
\hline \multicolumn{4}{|c|}{ Dobutamine, $\mu \mathrm{g} / \mathrm{kg} / \mathrm{min}$} \\
\hline I & $0(0-21)$ & $0(0-22)$ & 0.23 \\
\hline $\mathrm{H}$ & $0(0-21)$ & $12(0-30)$ & 0.11 \\
\hline $\mathrm{F}$ & $0(0-5)$ & $5(0-30)$ & 0.07 \\
\hline \multicolumn{4}{|c|}{ Norepinephrine, $\mu \mathrm{g} / \mathrm{kg} / \mathrm{min}$} \\
\hline I & $0(0-0.16)$ & $0(0-0.13)$ & 0.15 \\
\hline $\mathrm{H}$ & $0.05(0-0.21)$ & $0.24(0-0.34)$ & 0.004 \\
\hline $\mathrm{F}$ & $0(0-0.16)$ & $0.14(0-0.34)$ & 0.002 \\
\hline
\end{tabular}

Median (range) and Mann-Whitney $U$ test

$I L-6$ (8) interleukin-6 (8), TNF- $\alpha$ tumor necrosis factor alpha, $I$ initial, $H$ highest, $F$ final values in the course of time

TNF- $\alpha$ levels and dobutamine doses in those patients receiving the drug. Other associations were observed between dopamine doses and IL-6 levels and, inversely, between norepinephrine doses and IL-8 and TNF- $\alpha$ levels, in some multivariable models. In any case, none of the vasopressor/inotropic drugs was associated with elastase- $\alpha_{1}$-antitrypsin levels.

\section{DISCUSSION}

Our observations suggest that, in the treatment of human septic shock, dobutamine increases circulating TNF- $\alpha$ and dopamine increases IL- 6 , independently of disease severity, hemodynamics, and outcome. Conversely,

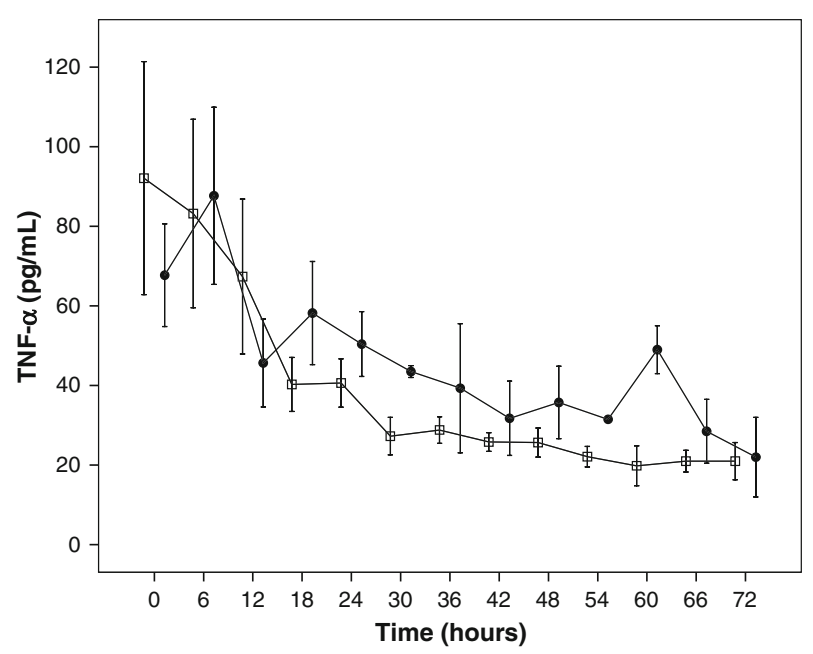

Fig. 1. Course of TNF- $\alpha$ plasma levels in seven septic shock patients with (filled circles) and 13 patients without (open squares) dobutamine infusion at six-hourly time points for the first $72 \mathrm{~h}$ after inclusion. Values are mean $\pm \mathrm{SEM} ; P=0.018$ (GEE).

norepinephrine may lack pro-inflammatory properties. The differences between dobutamine and dopamine suggest that $\beta$ and dopaminergic actions were involved, respectively.

The immune alterations, hemodynamic abnormalities, and associations with mortality in our patients agree with previous reports $[1-5,28]$. The positive association and relation between increases in TNF- $\alpha$ with increasing doses of dobutamine, a $\beta_{1}$ - and a weak $\alpha_{1}$ - and $\beta_{2}$-adrenergic receptor agonist, agrees with the literature suggesting dobutamine- and not enoximoneinduced secretion of TNF- $\alpha$ in isolated hepatocytes and the hepatosplanchnic region of septic shock patients [7, 26]. It may not agree with the lack of effect of the drug in the human endotoxemia model [25] and the inhibition of TNF- $\alpha$ and IL-8 secretion in endotoxin-challenged isolated (human) monocytes and whole blood by $\beta$ adrenergic receptor actions $[9,13,15,20]$. Indeed, circulating leukocytes may not be the source of the TNF$\alpha$ increase by dobutamine in our study, since the drug did not affect levels of neutrophilic elastase- $\alpha_{1}$-antitryp$\sin$. Nevertheless, our data may also be in line with the proinflammatory effect of $\beta$-receptor stimulation enhancing IL-6 and IL-8 production in endotoxin-challenged human monocytes, whole blood, or endothelial cells in vitro [11, $14,18]$. Moreover, the inverse association between TNF- $\alpha$ and IL- 8 on the one hand and doses of norepinephrine, an $\alpha_{1,2}$-and weak $\beta_{1}$-agonist, on the other further supports involvement of $\beta_{1}$-receptors in the potentially pro-inflammatory effect of dobutamine. On the other hand, the data 
Table 4. Generalized Estimating Equations for Pro-Inflammatory Mediators and Vasopressor/Inotropic Doses

\begin{tabular}{|c|c|c|c|c|c|c|c|c|}
\hline & \multicolumn{2}{|c|}{ IL-6 (pg/mL) } & \multicolumn{2}{|c|}{ IL-8 (pg/mL) } & \multicolumn{2}{|c|}{$\mathrm{TNF}-\alpha(\mathrm{pg} / \mathrm{mL})$} & \multicolumn{2}{|c|}{ Elastase- $\alpha_{1}$-antitrypsin $(\mathrm{ng} / \mathrm{mL})$} \\
\hline & $B$ & $P$ & $B$ & $P$ & $B$ & $P$ & $B$ & $P$ \\
\hline \multicolumn{9}{|l|}{ Univariable: } \\
\hline Dopamine, $\mu \mathrm{g} / \mathrm{kg} / \mathrm{min}$ & 0.33 & 0.03 & & 0.48 & & 0.85 & & 0.77 \\
\hline Dobutamine, $\mu \mathrm{g} / \mathrm{kg} / \mathrm{min}$ & & 0.19 & & 0.89 & 0.24 & 0.01 & & 0.26 \\
\hline Norepinephrine, $\mu \mathrm{g} / \mathrm{kg} / \mathrm{min}$ & & 0.57 & & 0.10 & -0.30 & 0.03 & & 0.17 \\
\hline \multicolumn{9}{|l|}{ Multivariable: } \\
\hline Dopamine, $\mu \mathrm{g} / \mathrm{kg} / \mathrm{min}$ & 0.33 & 0.02 & & 0.08 & & 0.74 & & 0.53 \\
\hline Dobutamine, $\mu \mathrm{g} / \mathrm{kg} / \mathrm{min}$ & & 0.40 & & 0.80 & 0.36 & $<0.001$ & & 0.24 \\
\hline Norepinephrine, $\mu \mathrm{g} / \mathrm{kg} / \mathrm{min}$ & & 0.70 & -0.22 & 0.02 & -0.38 & 0.04 & & 0.15 \\
\hline APACHE-II & -0.35 & 0.04 & & 0.91 & & 0.06 & & 0.36 \\
\hline Dopamine, $\mu \mathrm{g} / \mathrm{kg} / \mathrm{min}$ & & 0.06 & & 0.16 & & 0.85 & & 0.22 \\
\hline Dobutamine, $\mu \mathrm{g} / \mathrm{kg} / \mathrm{min}$ & & 0.87 & & 0.69 & 0.21 & 0.02 & & 0.27 \\
\hline Norepinephrine, $\mu \mathrm{g} / \mathrm{kg} / \mathrm{min}$ & & 0.51 & -0.23 & 0.01 & & 0.10 & & 0.06 \\
\hline MAP & -0.28 & 0.01 & & 0.06 & & 0.18 & 0.09 & 0.004 \\
\hline Dopamine, $\mu \mathrm{g} / \mathrm{kg} / \mathrm{min}$ & 0.40 & 0.01 & & 0.31 & & 0.82 & & 0.64 \\
\hline Dobutamine, $\mu \mathrm{g} / \mathrm{kg} / \mathrm{min}$ & & 0.29 & & 0.77 & 0.60 & $<0.001$ & & 0.43 \\
\hline Norepinephrine, $\mu \mathrm{g} / \mathrm{kg} / \mathrm{min}$ & & 0.84 & & 0.07 & & 0.45 & & 0.42 \\
\hline $\mathrm{CI}, \mathrm{L} / \mathrm{min} / \mathrm{m}^{2}$ & 0.51 & 0.002 & & 0.17 & 0.20 & 0.02 & & 0.11 \\
\hline
\end{tabular}

Only statistically significant regression coefficients are shown

$I L-6$ (8) interleukin-6 (8), TNF- $\alpha$ tumor necrosis factor-alpha, APACHE-II Acute Physiology and Chronic Health Evaluation-II score, MAP mean arterial pressure, $C I$ cardiac index, $B$ standardized regression coefficient

may explain in part the detrimental effects of high-dose dobutamine used in previous studies to increase tissue oxygen delivery to supranormal levels in shock states that may otherwise be beneficial [20].

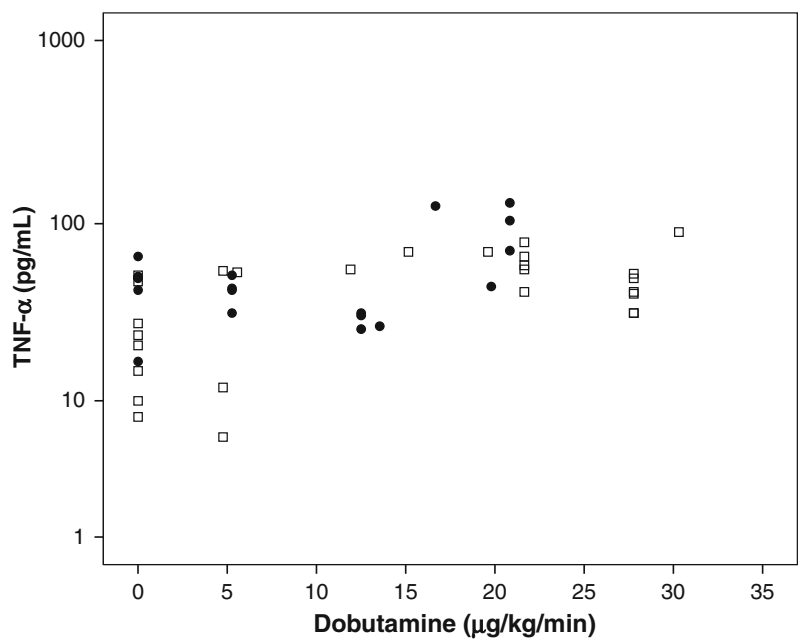

Fig. 2. Scatterplot of pooled data of (logarithmic) TNF- $\alpha$ plasma levels against dobutamine doses given in seven patients with septic shock treated with help of dobutamine (any dose), at six-hourly time points for the first $72 \mathrm{~h}$ after inclusion for observations when dobutamine was given, partial $r=0.29, P=0.06$ in survivors (filed circles) and $r=0.42, P=0.001$ in nonsurvivors (open squares).
Alpha- and $\beta$-receptor stimulation may have opposing effects on TNF- $\alpha$ production in vitro, since (endogenous) $\alpha_{2}$-receptor stimulation may stimulate TNF- $\alpha$ production by macrophages and Kupffer cells in some experimental studies [19] but not in others [17], and in vivo reports are scarce [10, 16, 22]. The negative associations between TNF- $\alpha$ and IL- 8 levels and norepinephrine dosing, however, suggests an anti-inflammatory effect by norepinephrine via $\alpha$ receptor stimulation in septic shock, as suggested before to occur in septic patients [9]. In contrast, dopamine treatment was associated with increased IL6 levels in most models evaluated, suggesting IL-6 release by endothelium or hepatocytes by $\mathrm{D}_{2}$ receptors, as reported $[7,8,11,21]$. In any case, the effect of dopamine, having $\beta_{1^{-}}$and $\alpha_{1}$-adrenergic properties also [8], may have been different from that of dobutamine and norepinephrine, thereby favoring predominant dopaminergic effects. Stress or catecholamines have also been implicated in the regulation of IL-10 $[8,9,14,18]$, which we did not measure, so we cannot exclude that alterations in the latter did underlie some of the reported associations and relations. Nevertheless, potentially less pro-inflammatory effects of norepinephrine than of dopamine and 
dobutamine may explain in part a better outcome of use of the former in the treatment of shock in the observational SOAP study [24]. In the study by De Backer, norepinephrine- and dopamine-treated patients had similar mortality, but adverse events were more frequent with the latter [29]. Otherwise, the lack of potential effect of catecholamines used in the treatment of septic shock on neutrophil activation agrees with a previous study in healthy volunteers [30], but contrasts with aggravation and amelioration of endotoxin-induced lung injury in rats by $\alpha_{1}$ - and $\alpha_{2}$-receptor actions on neutrophils, respectively [6].

The limitations of our study include relatively small number of patients and, by virtue of study design, evidence on the basis of statistical associations and relations only, so that results should be interpreted cautiously. For instance, the predictive value of circulating pro-inflammatory mediators for outcome, reported by others [1-5], could not be confirmed, except for IL-8, by our small study and limited period of observation. On the other hand, analyses were adjusted for disease severity, hemodynamics, and outcome, so that the positive relation between dobutamine doses and TNF- $\alpha$ levels in the early course of disease may reflect cause effect relations, rather than a common origin, i.e., severe shock with TNF- $\alpha$ induced myocardial depression necessitating dobutamine treatment and being associated with demise [28]. Indeed, this is the first study, to our knowledge, to address the in vivo immune-modulating effect of various catecholamines used early in the management of septic shock, independently of disease severity, hemodynamics, and outcome. Prospective evaluations of drug effects in septic shock may wish to include pro-inflammatory mediator levels. In fact, our observations argue in favor of immunosurveillance in future studies on the hemodynamic management of human septic shock with help of vasopressor/inotropic drugs.

In conclusion, our prospective observations suggest that catecholamines used early in the treatment of human septic shock differ in their potential to modulate the innate immune response to sepsis in vivo, by differing adrenergic and dopaminergic receptor stimulation.

Open Access. This article is distributed under the terms of the Creative Commons Attribution Noncommercial License which permits any noncommercial use, distribution, and reproduction in any medium, provided the original author(s) and source are credited.

\section{REFERENCES}

1. Bozza, F.A., J.L. Salluh, A.M. Japiassu, M. Soares, E.F. Assis, R. N. Gomes, M.T. Bozza, H.C. Castro-Faria-Neto, and P.T. Bozza. 2007. Cytokine profiles as markers of disease severity in sepsis: A multiplex analysis. Critical Care 11: R49.

2. Damas, P., J.L. Canivet, D. de Grootte, Y. Vrindts, A. Albert, P. Franchimont, and M. Lamy. 1997. Sepsis and serum cytokine concentrations. Critical Care Medicine 25: 405-412.

3. Hack, C.E., E.R. de Groot, R.J.F. Felt-Bersma, J.H. Nuijens, R.J. M. Strack van Schijndel, A.J.M. Eerenberg-Belmer, L.G. Thijs, and L.A. Aarden. 1989. Increased plasma levels of interleukin-6 in sepsis. Blood 74: 1704-1710.

4. Pinsky, M.R., J.-L. Vincent, J. Deviere, M. Alegre, R.J. Kahn, and E. Dupont. 1993. Serum cytokine levels in human septic shock. Relation to multiple organ failure and mortality. Chest 103: 565575 .

5. Riché, F.C., B. Cholley, Y.H. Panis, M.J. Laisné, C.G. Briard, A. M. Graulet, J. Guéris, and P. Valleur. 2000. Inflammatory cytokine response in patients with septic shock secondary to generalized peritonitis. Critical Care Medicine 28: 433-437.

6. Abraham, E., D.J. Kaneko, and R. Shenkar. 1999. Effects of endogenous and exogenous catecholamines on LPS-induced neutrophil trafficking and activation. The American Journal of Physiology 276: L1-L8.

7. Aninat, C., P. Seguin, P.-N. Descheemaeker, F. Morel, Y. Malledant, and A. Guillouzo. 2007. Catecholamines induce an inflammatory response in human hepatocytes. Critical Care Medicine 36: 848-854.

8. Beck, G.C., P. Brinkkoetter, C. Hanusch, J. Schulte, K. van Ackern, F.J. van der Woude, and B.A. Yard. 2004. Clinical review: Immunomodulating effects of dopamine in general inflammation. Critical Care 8: 485-491.

9. Bergmann, M., A. Gornikiewicz, T. Sautner, E. Waldmann, T. Weber, M. Mittlböck, E. Roth, and R. Függer. 1999. Attenuation of catecholamine-induced immunosuppression in whole blood from patients with sepsis. Shock 12: 421-427.

10. Flierl, M.A., D. Rittisch, M. Huber-Lang, J.V. Sarma, and P.A. Ward. 2008. Catecholamines - crafty weapons in the inflammatory arsenal of immune/inflammatory cells or opening Pandora's box? Molecular Medicine 14: 195-204.

11. Gornikiewicz, A., T. Sautner, C. Brostjan, B. Schmierer, R. Függer, E. Roth, F. Mühlbacher, and M. Bergmann. 2000. Catecholamines up-regulate lipopolysaccharide-induced IL-6 production in human microvascular endothelial cells. The FASEB Journal 14: 10931100.

12. Groeneveld, A.B.J. 2006. Catecholamines, parasympathetic stimuli, or cortisol for overwhelming sepsis? Critical Care Medicine 34: $1549-1550$.

13. Guirao, X., A. Kumar, J. Katz, M. Smith, E. Lin, C. Keogh, S.E. Calvano, and S.F. Lowry. 1997. Catecholamines increase monocyte TNF receptors and inhibit TNF through $\beta_{2}$-adrenoreceptor activation. The American Journal of Physiology 273: E1203E1208.

14. Kavelaars, A., M. van de Pol, J. Zijlstra, and C.J. Heijnen. 1997. $\beta_{2}$ adrenergic activation enhances interleukin- 8 production by human monocytes. Journal of Neuroimmunology 77: 211-216.

15. Li, C.-Y., C.-S. Tsai, P.-C. Hsu, C.-T. Wu, C.-S. Wong, and S.-T. Ho. 2003. Dobutamine modulates lipopolysaccharide-induced macrophage inflammatory protein- $1 \alpha$ and interleukin- 8 production in human monocytes. Anesthesia and Analgesia 97: 210-215.

16. Miksa, M., P. Das, M. Zhou, R. Wu, W. Dong, Y. Ji, S.M. Goyert, T.S. Ravikumar, and P. Wang. 2009. Pivotal role of the alpha(2A)- 
adrenoceptor in producing inflammation and organ injury in a rat model of sepsis. PLOS ONE 4: e5504.

17. Morgan, J.H., T.C. Gamblin, J.R. Adkins, J.R. Groves, M.L. Dalton, and D.W. Ashley. 2004. Norepinephrine is a more potent inhibitor of tumor necrosis factor over a range of doses than dopamine. American Journal of Surgery 70: 526-528.

18. Van der Poll, T., and S.F. Lowry. 1997. Lipopolysaccharideinduced interleukin-8 production by human whole blood is enhanced by epinephrine and inhibited by hydrocortisone. Infection and Immunity 65: 2378-2381.

19. Spengler, R.N., R.M. Allen, D.G. Remick, R.M. Strieter, and S.L. Kunkel. 1990. Stimulation of alpha-adrenergic receptor augments the production of macrophage-derived tumor necrosis factor. Journal of Immunology 145: 1430-1434.

20. Uusaro, A., and J.A. Russell. 2000. Could anti-inflammatory actions of catecholamines explain the possible beneficial effects of supranormal oxygen delivery in critically ill surgical patients? Intensive Care Medicine 26: 299-304.

21. Yang, M., H. Zhang, T. Voyno-Yasenetskaya, and R.D. Ye. 2003. Requirement of Gbetagamma and c-Src in $\mathrm{D}_{2}$ dopamine receptormediated nuclear factor-kappaB activation. Molecular Pharmacology 64: 447-455.

22. Yang, S., M. Zhou, I.H. Chaudry, and P. Wang. 2001. Norepinephrineinduced hepatocellular dysfunction in early sepsis is mediated by activation of $\alpha_{2}$-adrenoceptors. American Journal of Physiology. Gastrointestinal and Liver Physiology 281: G1014-G1021.

23. Póvoa, P.R., A.H. Carneiro, O.S. Ribeiro, A.C. Pereira, and on behalf of the Portuguese Community-Acquired Sepsis Study Group. 2009. Influence of vasopressor agent in septic shock mortality. Results from the Portuguese Community-Acquired Sepsis Study (SACiUCI study). Critical Care Medicine 37: 410-416.
24. Sakr, Y., K. Reinhart, J.-L. Vincent, C.L. Sprung, R. Moreno, V.M. Ranieri, D. de Backer, and D. Payen. 2006. Does dopamine administration in shock influence outcome? Results of the sepsis occurrence in acutely ill patients (SOAP) study. Critical Care Medicine 34: 589-597.

25. Lemaire, L.C., M.D. de Kruijf, I.A. Giebelen, M. Levi, T. van der Poll, and M. Heesen. 2006. Dobutamine does not influence inflammatory pathways during human endotoxemia. Critical Care Medicine 34: 1365-1371.

26. Kern, H., T. Schröder, M. Kaulfuss, M. Martin, W.J. Kox, and C.D. Spies. 2001. Enoximone in contrast to dobutamine improves hepatosplanchnic function in fluid-optimized septic shock patients. Critical Care Medicine 29: 1519-1525.

27. Flierl, M.A., D. Rittisch, M.B.A. Nadeau, J.V. Sarma, D.E. Day, A. B. Lentsch, M. Huber-Lang, and P.A. Ward. 2009. Upregulation of phagocyte-derived catecholamines augments the acute inflammatory response. PLOS ONE 4: e4414.

28. Hartemink, K.J., A.B.J. Groeneveld, M.C.M. de Groot, R.J.M. Strack van Schijndel, G. van Kamp, and L.G. Thijs. 2001. alphaAtrial natriuretic peptide, cyclic guanosine monophosphate, and endothelin in plasma as markers of myocardial depression in human septic shock. Critical Care Medicine 29: 80-87.

29. De Backer, D., P. Biston, J. Devriendt, C. Madl, D. Chochrad, C. Aldecoa, A. Brasseur, P. Defrance, P. Gottignies, J.-L. Vincent, and SOAPII Investigators. 2010. Comparison of dopamine and norepinephrine in the treatment of shock. The New England Journal of Medicine 362: 779-789.

30. Burns, A.M., M. Keogan, M. Donaldson, D.L. Brown, and G.R. Park. 1997. Effects of inotropes on human leucocyte numbers, neutrophil function and lymphocyte subtypes. British Journal of Anaesthesiology 78: 530-535. 